\title{
Reversible cerebral vasoconstriction syndrome presenting with intracranial hemorrhage: a case report and literature review
}

\author{
Tae Won Choi, Hee Sup Shin, Seung Hwan Lee, Jun Seok Koh, Hak Cheol Ko \\ Department of Neurosurgery, Kyung Hee University Hospital at Gangdong, Kyung Hee University School of Medicine, Seoul, Korea
}

Reversible cerebral vasoconstriction syndrome (RCVS) is characterized by a severe thunderclap headache associated with segmental vasoconstriction of the cerebral arteries. RCVS may result in intracranial hemorrhage (ICH), but the pathophysiology and data of RCVS-related ICH are not well known. The authors report a case of RCVS that presented with intraparenchymal hemorrhage (IPH) and subarachnoid hemorrhage (SAH). A 66-year-old female presented with recurrent thunderclap headache, and her initial consciousness and neurologic status were normal. Brain computed tomography (CT) revealed IPH in the left frontal cortex and SAH in the left Sylvian fissure. CT angiography and digital subtraction angiography showed multiple segmental vasoconstrictions in the M3 segments of the left middle cerebral artery, but intracranial aneurysm or vascular malformation was not observed. After nimodipine infusion and pain control, the headache subsided, and she was discharged without neurologic deficits. Three months after symptom onset, the segmental vasoconstrictions disappeared on cerebral magnetic resonance angiography. Clinicians should be aware of RCVS as a possible cause of non-aneurysmal SAH and IPH in an unusual location.

Keywords: Vasoconstriction; Subarachnoid hemorrhage; Intracranial hemorrhages; Headache

\section{Introduction}

Reversible cerebral vasoconstriction syndrome (RCVS) is characterized by recurrent thunderclap headaches with segmental vasoconstriction of the intracranial arteries. RCVS may result in ischemic stroke or intracranial hemorrhage (ICH), but the pathophysiology and data of RCVS-related ICH are not well known [1]. The purpose of this case report is to discuss the process of diagnosis of RCVS when ICH is accompanied by severe headache on patients without a specific medical history.

\section{Case Report}

A 66-year-old female with no specific medical history presented

Received: July 5, 2021

Revised: August 17, 2021

Accepted: September 9, 2021

Corresponding Author: Hee Sup Shin, MD, PhD

Department of Neurosurgery, Kyung Hee University Hospital at Gangdong, 892 Dongnam-ro, Gangdong-gu, Seoul 05278, Korea

Tel: +82-2-440-6090; Fax: +82-2-440-8404;

E-mail: realeponym@hanmail.net with a sudden onset headache during the early morning on the day of the visit. The headache improved after taking acetaminophen (500 mg, Tylenol; Janssen Korea, Seoul, Korea), but the pain recurred shortly. She visited the emergency room and complained of a severe headache. The patient was alert and had no neurological abnormalities. Brain computed tomography $(\mathrm{CT})$ revealed intraparenchymal hemorrhage (IPH) on the left frontal cortex with subarachnoid hemorrhage (SAH) on the left Sylvian fissure, suprasellar cistern, and perimesencephalic cistern (Fig. 1A, 1B). Multiple segmental vasoconstrictions on the M3 segments of the left middle cerebral artery (MCA) were revealed on brain CT angiography and subsequent digital subtraction angiography (DSA) (Fig. 1C, 1D). No vascular malformations such as aneurysms, arteriovenous malformations, arteriovenous fistulas, or dissections were observed.

After admission, continuous intravenous infusion of nimodipine ( $2 \mathrm{mg} / \mathrm{hr}$ ) was administered with pain control. Brain CT with perfusion study was performed on the eighth day after symptom onset. The ICH was resolving, and there were no abnormalities in blood flow other than the perfusion defect on the region of the ICH (Fig. 2). We changed the nimodipine administration from in- 

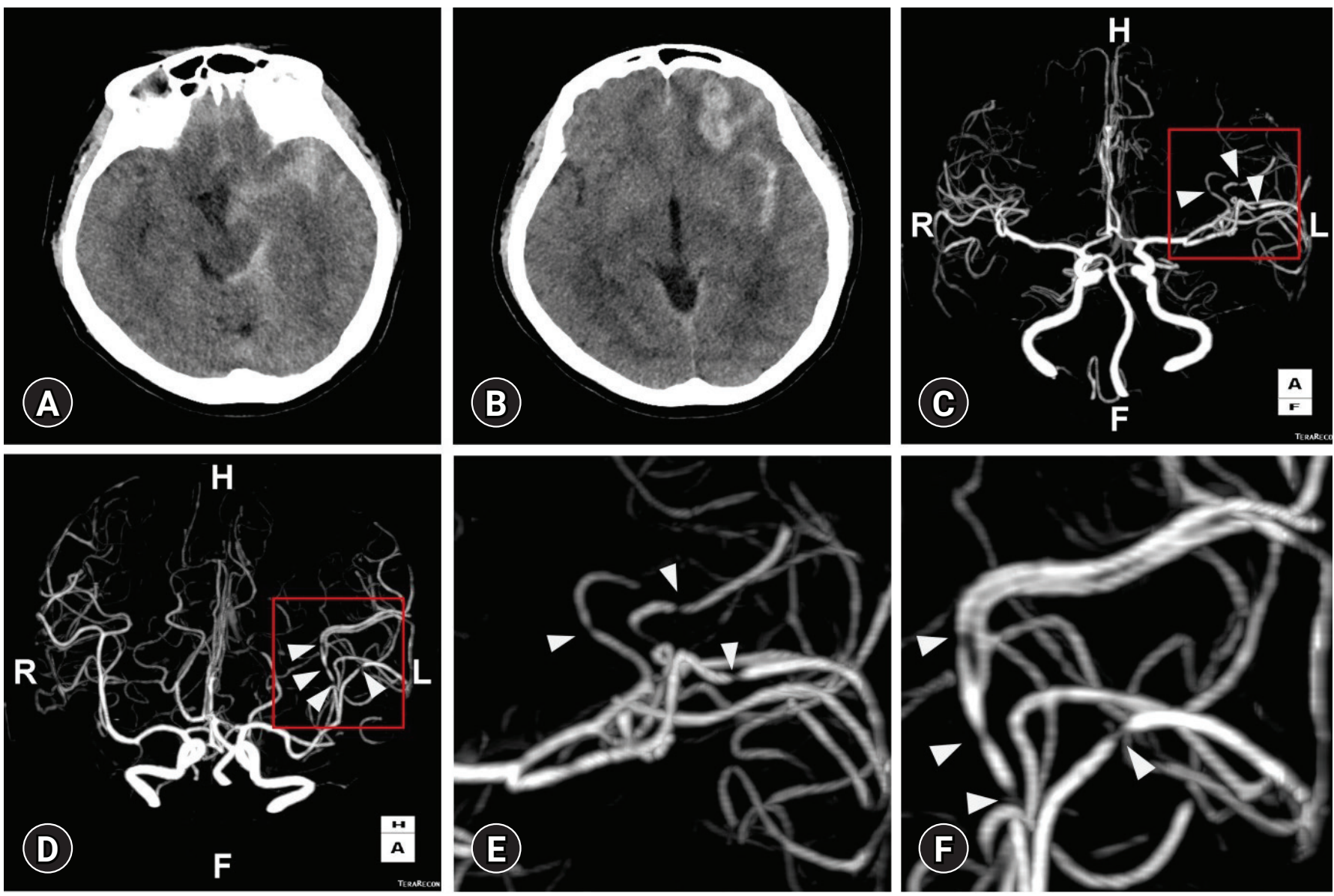

Fig. 1. Brain computed tomography (CT) at symptom onset. CT scans show intraparenchymal hemorrhage in the left frontal cortex with subarachnoid hemorrhage in the left Sylvian fissure, suprasellar cistern, and perimesencephalic cistern (A, B). Multiple segmental vasoconstrictions in the M3 segments of the left middle cerebral artery are observed on brain CT angiography (white arrowheads; C, D). The boxed areas are magnified in (E) and (F).
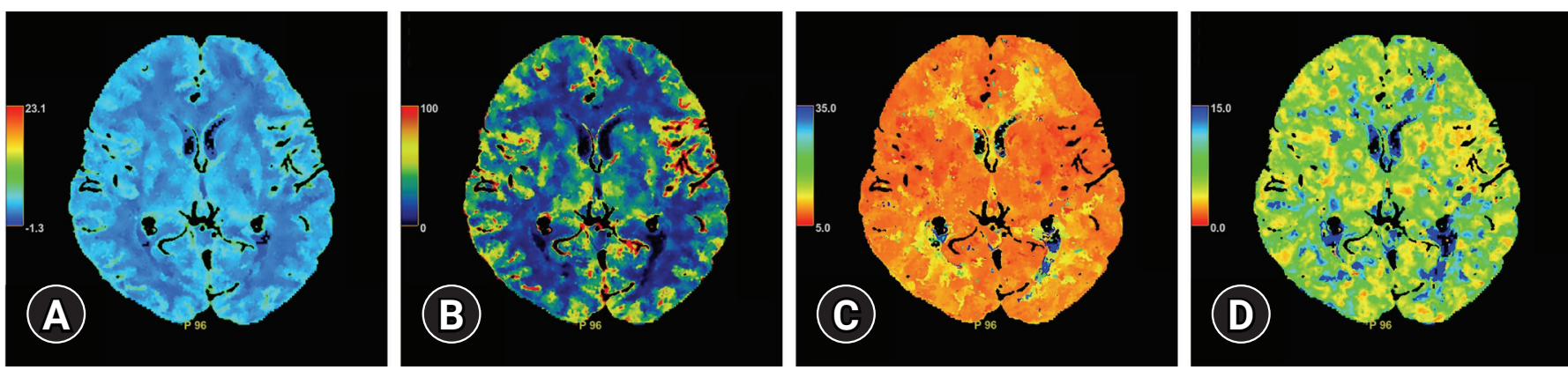

Fig. 2. Brain computed tomography with perfusion study on the eighth day after symptom occurrence. No abnormalities in (A) blood volume and (B) blood flow were observed, with normal (C) time-to-peak and (D) mean transit time.

travenous infusion to per-oral ( $60 \mathrm{mg}, 3$ times/day). During the admission period, there was no change in the patient's consciousness or neurological symptoms. For evaluating risk factors of RCVS, we checked patient's history of disease, coitus, exercise, and medication (hormone and vasoconstrictors). However, we failed to find out the trigger point of RCVS. The headache gradually im- proved, and she complained of only mild headaches. After discharge from the hospital, we maintained nimodipine therapy $(60$ $\mathrm{mg}, 3$ times/day) for 14 days along with pain control. Three months after symptom onset, we performed brain magnetic resonance (MR) images for follow-up checks, which showed diffuse cortical hemosiderosis on the left Sylvian fissure and frontoparietal 
sulci (Fig. 3A, 3B). No segmental vasoconstrictions were observed on MR angiography (Fig. 3C, 3D). Written informed consent was obtained for publication of this case report and accompanying images.

\section{Discussion}

RCVS is characterized by a severe thunderclap headache associated with segmental vasoconstrictions of cerebral arteries. RCVS is diagnosed by DSA or CT angiography showing vasoconstrictions of the cerebral arteries in at least two parts and disappearing within 3 months in brain imaging studies [1]. RCVS can occur at any age and is known to be more common in women [2-5]. Although the actual incidence of RCVS is not certain, several studies show that it is not uncommon $[1,6-8]$. The incidence rate seems to increase in recent years, but it is thought to be reflected the increase in the diagnosis due to the development of imaging technology $[2,7,9]$. The pathophysiology of RCVS is not clearly defined. Sympathetic excitation by medication, endothelial dysfunction, and oxidative stress can cause RCVS. Several risk factors are reported in the literatures. Postpartum state, migraine, head trauma, and drugs may be involved in RCVS, which is thought to be due to hormonal and biochemical factors related to vasodilation, such as estrogen, endocellin-1, serotonin, or nitric oxide $[4,7,10-12]$.

The chief complaint of most patients is bilateral and diffuse thunderclap headache initiating from the occipital area $[3,4,13]$.
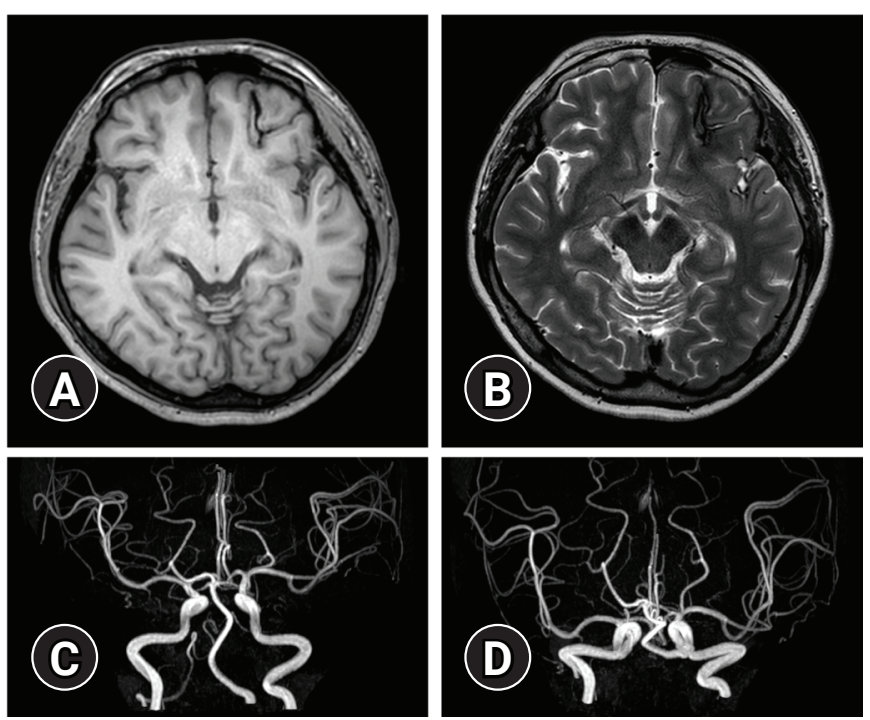

Fig. 3. Brain magnetic resonance (MR) image 3 months after from symptom onset. Diffuse cortical hemosiderosis in the left Sylvian fissure and frontoparietal sulci was revealed on (A) T1-weighted and (B) T2-weighted MR image. (C, D) No segmental vasoconstrictions were observed on MR angiography.
The focal neurologic deficit, seizures, and cortical SAH also followed [1]. Treatment is the cessation of the triggers such as drugs with close observation in the intensive care unit with control the pain, blood pressure, seizure $[2,3,7]$. The prognosis of most patients is good, and recurrence is rare $[1,7]$.

ICH incidence in RCVS is $34 \%$ to $43 \%$, and focal cortical SAH of $30 \%$ to $35 \%$ has been reported through a single-center study $[14,15]$. Although the mechanism of SAH in RCVS is not well known, disruption of pial vessels and reperfusion injury through high flow in constricted arteries can cause SAH [16]. It is challenging to diagnose RCVS involved SAH, because clinical symptom and radiologic findings are similar to aneurysmal SAH [17]. The pattern of focal SAH is mainly observed on non-contrast images, but aneurysmal SAH mostly shows bleeding in the basal cistern, which helps to differentiate $[3,7,8,11]$. Although it may be difficult to determine RCVS with SAH from arterial vasospasm caused by $\mathrm{SAH}$, Ansari et al. [11] compared these two diseases. They suggested some helpful imaging criteria for diagnosis (Table 1). In $\mathrm{SAH}$, it is easy to observe the narrowing of blood vessels because DSA is performed immediately. However, if only ICH is present, the DSA, MR angiography, and CT angiography will be examined at time intervals. Because of this, the examination may proceed after the stenosis has disappeared, making the diagnosis difficult. Besides hemorrhage or infarction, vascular dissection are sometimes accompanied, and patients usually have a severe headache that is different from general migraine and spreads bilaterally $[1,10]$. Rarely, mild headache may occur, and ICH may occur due to vasoconstriction in the early stages of RCVS.

In this case, the patient showed SAH with IPH on non-contrast $\mathrm{CT}$, and vasoconstriction was observed at the initial $\mathrm{CT}$ angiography. Although intracranial aneurysms and other vascular malformations were not revealed on CT angiography, we performed DSA to confirm the exclusion of intracranial vascular lesions. The typical pattern of SAH in RCVS patients is cortical SAH; however, the patient's SAH was very similar to that of aneurysmal SAH. The repeated DSA and CT angiography showed no aneurysm or vascular dissection neither, but we could observe the vasoconstriction of multiple segments on M3 segments of MCA. After careful inspection of image workup, we could suggest the cause of SAH as RCVS despite the similar hemorrhagic pattern of aneurysmal SAH.

\section{Conclusion}

As the rate of diagnosis of cerebrovascular diseases increases with the development of imaging technology, the rate of diagnosis of RCVS is also growing. However, clinically, it is still difficult to diagnose RCVS in patients with a severe headache accompanied by 
Table 1. Differential diagnostic criteria for RCVS-associated SAH from vasospasm after aneurysmal SAH [11]

\begin{tabular}{ll}
\hline RCVS vasoconstriction & \multicolumn{1}{c}{ Vasospasm-aneurysmal SAH } \\
\hline $\begin{array}{l}\text { No evidence of ruptured aneurysm or vascular malformation } \\
\text { Diffuse and disproportionate extent of cerebral vasoconstriction } \\
\text { relative to the extent of SAH }\end{array}$ & $\begin{array}{l}\text { Plausible target lesion identified } \\
\text { Severity of vasospasm correlates with amount of hemorrhage } \\
\text { and is most pronounced in the vicinity of the lesion }\end{array}$ \\
$\begin{array}{l}\text { Beaded or sausage-shaped appearance of alternating areas of } \\
\text { segmental vasoconstriction preferentially involving distal }\end{array}$ & $\begin{array}{l}\text { Smooth, long segmental narrowing of the proximal arteries at the } \\
\text { circle of Willis }\end{array}$ \\
$\begin{array}{l}\text { second- and third-order cerebral branches } \\
\text { Development of vasoconstriction in the first } 4 \text { to } 5 \text { days after symptom } \\
\text { onset, or persistence past } 3 \text { weeks }\end{array}$ & $\begin{array}{l}\text { Development of vasospasm peaking between } 4 \text { and } 14 \text { days } \\
\text { after hemorrhage }\end{array}$
\end{tabular}

RCVS, reversible cerebral vasoconstriction syndrome; SAH, subarachnoid hemorrhage.

SAH or ICH. In case of non-aneurysmal SAH and IPH in an unusual location, clinicians should be aware of RCVS as a possible cause of SAH and IPH, and careful inspection of image workup is mandatory.

\section{Conflicts of interest}

No potential conflict of interest relevant to this article was reported.

\section{ORCID}

Tae Won Choi, https://orcid.org/0000-0001-7914-3095

Hee Sup Shin, https://orcid.org/0000-0002-5286-8448

Seung Hwan Lee, https://orcid.org/0000-0001-8043-632X

Jun Seok Koh, https://orcid.org/0000-0003-1576-134X

Hak Cheol Ko, https://orcid.org/0000-0001-8745-3309

\section{REFERENCES}

1. Ducros A. Reversible cerebral vasoconstriction syndrome. Lancet Neurol 2012;11:906-17.

2. Ducros A. L37. Reversible cerebral vasoconstriction syndrome: distinction from CNS vasculitis. Presse Med 2013;42(4 Pt 2):602-4.

3. Ducros A, Bousser MG. Reversible cerebral vasoconstriction syndrome. Pract Neurol 2009;9:256-67.

4. Calabrese LH, Dodick DW, Schwedt TJ, Singhal AB. Narrative review: reversible cerebral vasoconstriction syndromes. Ann Intern Med 2007; 146:34-44.

5. Liu HY, Fuh JL, Lirng JF, Chen SP, Wang SJ. Three paediatric patients with reversible cerebral vasoconstriction syndromes. Cephalalgia 2010;30:354-9.

6. Probert R, Saunders DE, Ganesan V. Reversible cerebral vasoconstriction syndrome: rare or underrecognized in children? Dev Med Child Neurol 2013;55:385-9.
7. Sheikh HU, Mathew PG. Reversible cerebral vasoconstriction syndrome: updates and new perspectives. Curr Pain Headache Rep 2014;18:414.

8. Singhal AB, Hajj-Ali RA, Topcuoglu MA, et al. Reversible cerebral vasoconstriction syndromes: analysis of 139 cases. Arch Neurol 2011;68:1005-12.

9. Wolff V, Lauer V, Rouyer O, et al. Cannabis use, ischemic stroke, and multifocal intracranial vasoconstriction: a prospective study in 48 consecutive young patients. Stroke 2011;42:1778-80.

10. Ducros A, Wolff V. The typical thunderclap headache of reversible cerebral vasoconstriction syndrome and its various triggers. Headache 2016;56:657-73.

11. Ansari SA, Rath TJ, Gandhi D. Reversible cerebral vasoconstriction syndromes presenting with subarachnoid hemorrhage: a case series. J Neurointerv Surg 2011;3:272-8.

12. Chen SP, Chung YT, Liu TY, Wang YF, Fuh JL, Wang SJ. Oxidative stress and increased formation of vasoconstricting F2-isoprostanes in patients with reversible cerebral vasoconstriction syndrome. Free Radic Biol Med 2013;61:243-8.

13. Cheng YC, Kuo KH, Lai TH. A common cause of sudden and thunderclap headaches: reversible cerebral vasoconstriction syndrome. J Headache Pain 2014;15:13.

14. Topcuoglu MA, Singhal AB. Hemorrhagic reversible cerebral vasoconstriction syndrome: features and mechanisms. Stroke 2016;47:1742-7.

15. Ducros A, Fiedler U, Porcher R, Boukobza M, Stapf C, Bousser MG. Hemorrhagic manifestations of reversible cerebral vasoconstriction syndrome: frequency, features, and risk factors. Stroke 2010;41:2505-11.

16. Edlow BL, Kasner SE, Hurst RW, Weigele JB, Levine JM. Reversible cerebral vasoconstriction syndrome associated with subarachnoid hemorrhage. Neurocrit Care 2007;7:203-10.

17. Nickele C, Muro K, Getch CC, Walker MT, Bernstein RA. Severe reversible cerebral vasoconstriction syndrome mimicking aneurysmal rupture and vasospasm. Neurocrit Care 2007;7:815 . 